\title{
The Impact of Organizational Justice on Organizational Citizenship Behavior in Malaysian Higher Education
}

\author{
Roslan Awang ${ }^{1^{*}}$ \\ Wan Mohd Rashid Wan Ahmad² \\ ${ }^{1}$ Kuala Terengganu Community College \\ 2Tun Hussein Onn University; "roslanclk@gmail.com
}

Doi:10.5901/mjss.2015.v6n5s2p674

\begin{abstract}
This study investigated the relationship between organizational justice and organizational citizenship behavior (OCB). The population is the academic staff in Malaysian polytechnic which was clustered into five regions (Northern, Central, Western, Eastern and Borneo) which involved 363 samples. The instruments used to collect data were adopted from established previous studies. The data were analyzed using descriptive statistics and regression analysis. The results show that there only distributive justice and interactional justice has a significant relationship of OCB. Finally, the findings have supported the social exchange theory.
\end{abstract}

Keywords: organizational citizenship behavior; organizational justice; academic staff;

\section{Introduction}

The factors of globalization and response to growing demands are some of the reasons driving organizational transformation. Hence, higher educational institution as the important provider of knowledge need to make efforts to transform themselves to become more effective and efficient entities. In line with the transformation, Malaysian polytechnics have launched the Polytechnic Transformation Agenda 2010-2020 to boost the image and increase the competitiveness among higher educational institutions (Jabatan Pengajian Politeknik, 2009). According to the blueprint, in the year 2015 this transformation has supposed to achieve three outcomes which are preferred institution, employable or entrepreneur graduates and positive perception of society. However, in many cases the organizations have failed to achieve transformation objective (Burke, 2008; Johnson-Cramer et al., 2007). This is due the success of transformation is generalized from the employee in the organization and the organization cannot transform themselves. In addition, the process can be highly complex and may counter several barriers arising from external and internal (Waheed et al., 2011).

In general, the process of transformation has some impact on behavior. The substantive changes in the work routine will inevitably create discomfort and dissonance between them. According to Kotter (2009), employees who feel comfortable with their daily routine will resist to make any changes. Furthermore, they need to alter both their behavior and attitude in appropriate ways to adapt to the new working process. Besides, when the transformation initiative is poorly implemented, it could damage their morale and affect their behavior (Leach, 2009; Seijts \& Roberts, 2011). As a result, employees play an important role towards activities in the organization such as their social interaction with colleagues and leaders to conduct the activities. The behavior of responsible, committed, brave and wise is considered the most basic to organization success (Jafari \& Bidarian, 2012). Researchers have agreed that this positive behavior towards organization is known as organizational citizenship behavior (Bateman \& Organ, 1983). This behavior is defined as the helpful, discretionary behavior exhibited that are not directly recognized by the rewards system and task performance. However, this behavior helps to facilitate the social process in an organization. Each individual behavior is different and cannot be prescribed in advance for a job given organization and thus are the voluntary in nature (Katz \& Kahn, 1966).

Many studies have been done to identify the factors that could enhance organizational citizenship behavior. Factors that relate to personal characteristics, organizational justice, organizational commitment and job satisfaction. However, these factors are limited in higher educational settings compared to the school and business studies. Although the educational institution performance is assessed by the student achievement, but the fundamental of the successfulness is the academic staff behaviors that are willing to go beyond the role of voluntary (DiPaola et al., 2001). Besides, how the organization treats the academic staff is also important. The organizational justice, such as procedure, 
leadership and implementation could encourage the level of organizational citizenship behavior. As a result, this study attempts to investigate the impact organizational justice (distributive, procedural and interactional) on organizational citizenship behavior.

\section{Literature Review and Hypothesis Development}

The concept of organizational citizenship behavior relies on the social exchange theory where person who obtain more support, trust, resource opportunities and other benefits from organization feel obligated to reciprocate (Blau, 1964). Distributive justice refers to what academic staff receive compares with the contribution they have made to organizations. According to Moon et al (2008), when individual are given fair rewards commensurate with what they have contributed, it is a sign that abilities are valued by the organization. Several researchers have argued that distributive justice has a positive impact on organizational citizenship behavior (Yaghoubi et al., 2012; Hemdi et al., 2012). Besides, the fair distribution in term of rewards, it will enhance academic staff to reciprocate the organizational citizenship behavior to their colleagues, leaders and organizations. Therefore, the following hypothesis is proposed. behavior

Hypothesis 1: There is no significant relationship between distributive justice and organizational citizenship

Besides, of distributive justice outcomes, academic staff also want to know the way judgement allocation has been made. This behavior introduces procedural justice is referred to the perception towards fairness of decision made by organizations. The decision is considered procedurally when it is consistently practiced all times. Hence, when academic staff sees certain procedures are fair, although they are not directly affected, they will respect as members of the organization. In education sector, the procedural justice is one indicator predicting organizational citizenship behavior (Zeinabadi \& Salehi, 2011). The fair of between academic staff and leadership will increase the trust between them. Based on this assumption, the following hypothesis is formed. behavior

Hypothesis 2: There is no significant relationship between procedural justice and organizational citizenship

Although the distributive justice and procedural justice are being performed in organizations, the perception of interpersonal fairness treatment received are important during the implementation of procedures. Therefore, the interactional justice is important to the quality of the relationship between academic staff individually and the organization. The unfavorable decision from organizations are considered fair when the academic staff is given sufficient explanation. Simultaneously, the academic staff reciprocates with organizational citizenship behavior. In education sector, academic staff spend most of their time teaching students and are not totally involved in administrative task. Hence, this show that interactional justice is less compared with distributive justice and procedural justice. The following hypothesis is formed:

Hypothesis 3: There is no significant relationship between interactional justice and organizational citizenship behavior.

\section{Methodology}

This study is the relationship between organizational justice and organizational citizenship behavior. The questionnaires have distributed to 363 respondents which is randomly selected from academic staff in Malaysian polytechnics. For organizational justice consists eighteen question (distributive, procedural and interactional). While, organizational citizenship consists 25 questionnaires (altruism, sportsmanship, courtesy, civic virtue and conscientiousness). The questions are according to seven types of Likert scale from ( $1=$ strongly disagree to $7=$ truly strongly agree). The validity of the questionnaires is verified by the expertise from the pilot study conducted. Meanwhile, to determine the reliability this used the Cronbach Alpha (organizational justice 0.85 and organizational citizenship behavior 0.88 ). The data analyses applying the descriptive analysis using the Pearson correlation and multivariate regression analysis. The analysis is to examine the correlation between two variables and also involve the demographic factors such as gender, marital status, age and educational background. 


\section{Results and Discussion}

Table 1. Descriptive Statistic Results $(N=363)$

\begin{tabular}{|l|c|c|c|c|}
\hline Variable & Mean & Std. Dev & Skewness & Kurtosis \\
\hline Distributive Justice & 4.76 & 1.26 & -0.56 & 0.19 \\
Procedural Justice & 4.46 & 1.13 & -0.61 & 0.35 \\
Interactional Justice & 4.75 & 1.07 & -0.45 & 0.29 \\
OCB & 5.39 & 0.59 & -0.34 & -0.13 \\
\hline
\end{tabular}

Table 1 displays the means, standard deviation, skewness and kurtosis of the data. While the social demographics are subsequently used as the control variable in the test hypotheses. In total, the mean score is above the midpoint of 4.0 on the rating scale. These findings in line with the study from Tanzania by Nguni et al., 2006, and Malaysia by Lee and Ahmad (2009). From the results, distribute justice mean score is higher (4.76) compared to the interactional justice (4.75) and procedural justice (4.46). These shows that the justice in this organization is accepted well by the academic staff. Also, by experiencing more organizational citizenship behaviour (OCB) (5.39), this means that the academic staff are committed to displaying behaviors that are volunteered (Meh \& Nasurdin, 2009; Erkutlu, 2011).

Table 2. Pearson Correlation Coefficients $(N=363)$

\begin{tabular}{|l|cccc|}
\hline Variable & 1 & 2 & 3 & 4 \\
\hline 1. Distributive Justice & 1 & $0.599^{\star *}$ & $0.607^{\star \star}$ & $0.306^{\star *}$ \\
2. Procedural Justice & $0.599^{\star \star}$ & 1 & $0.702^{\star \star}$ & $0.210^{\star *}$ \\
3. Interactional Justice & $0.607^{\star *}$ & $0.702^{\star *}$ & 1 & $0.324^{\star *}$ \\
4. OCB & $0.306^{\star \star}$ & $0.210^{\star *}$ & $0.324^{\star *}$ & 1 \\
\hline
\end{tabular}

${ }^{* *}$ Correlation is significant at 0.01 level (2-tailed).

Table 2 indicates that all correlations are found to be significant. Likewise, organizational justice dimensions are positively correlated with one another and organizational citizenship behavior. The strongest correlation is among procedural justice and interactional justice in 0.702 . The lowest correlation is among procedural justice and organizational citizenship behavior at 0.210 . According to Chua (2009), these correlations are medium range which is between 0.3 to 0.7 except for procedural justice and organizational citizenship behavior. From the analysis conducted shows that when the organizational justice dimensions is increase the organizational citizenship behavior is increasing. This parallel relationship is aligned with the previous study conducted by Salleh et al. (2013). The statistically significant intercorrelations between the independent and dependent might indicate the relationship with academic staff's organizational citizenship behavior.

Table 3. Hierarchical Regression $(N=363)$

\begin{tabular}{|l|cc|c|c|c|}
\hline & \multicolumn{2}{|c|}{ Unstandardized Coefficients } & \multicolumn{2}{|c|}{$\begin{array}{c}\text { Standardized Coefficients } \\
\text { Beta }\end{array}$} & Sig. \\
\hline (Constant) & B & Std. Error & \multicolumn{2}{c|}{ B } & \\
Gender & 4.22 & 0.20 & & 20.71 & 0.00 \\
Marital Status & -0.03 & 0.06 & -0.02 & -0.48 & 0.63 \\
Age & -0.15 & 0.08 & $-0.10^{\star *}$ & -1.93 & 0.05 \\
Education Level & 0.11 & 0.03 & $0.17^{\star \star *}$ & 3.21 & 0.00 \\
Distributive Justice & 0.04 & 0.05 & 0.04 & 0.82 & 0.41 \\
Procedural Justice & 0.09 & 0.03 & $0.19^{\star \star *}$ & 2.96 & 0.00 \\
Interactional Justice & -0.03 & 0.04 & -0.06 & -0.79 & 0.43 \\
$\mathrm{R}^{2}$ & 0.14 & 0.04 & $0.25^{\star \star *}$ & 3.47 & 0.00 \\
$\Delta \mathrm{R}^{2}$ & 0.158 & & & & \\
F-Value & 0.158 & & & & \\
\hline
\end{tabular}

a. Dependent variable: OCB

Notes: Significant at ${ }^{*} p<0.05,{ }^{*} p<0.01,{ }^{* \star} p<0.001$

The analysis for the hypothesis testing was conducted by using the multiple regression. Table 3 shows that the $\mathrm{R}^{2}$ value 
of 0.158 indicates that only $15.8 \%$ variance is explained by the independent variable. This variance is acceptable in the OCB studies. Based on previous study in Malaysia about reported OCB, $R^{2}$ is low which is 6\% (Idrus, 2007) and (Meh \& Nasurdin, 2009). Besides, the result of F-value is 9.511 which significant at $1 \%$ level. The relationships between the control variable and dependent are also different. The value of gender $(\beta=-0.02)$ and educational level $(\beta=0.04)$ are not significant with OCB. Naturally, women are to be more cautious in their jobs, thus they are more likely to perform an OCB. Further, the relationship between marital status $(\beta=-0.10)$ and age $(\beta=0.17)$ are significant with OCB. The negative sign of beta coefficient for gender shows that married academic staff has a lower tendency to perform an OCB. This result is consistent with the empirical evidence documented by Bolino et al. (2010). In spite of age, when the academic staff become older they tend to demonstrate a high level of OCB.

Meanwhile, the results for the distributive justice variable $(\beta=0.19)$ are significant in relation to OCB. This is shown that the fair distributive justice affects the academic staff to perform an OCB. Thus, the null hypothesis 1 is accepted. In contrast, the procedural justice variable $(-0.06)$ has no significant relationship with OCB. The negative sign shows that when the procedure in organizations is not rigid the organizational citizenship is increasing. This finding is contrary to the positive relationship found by Khan and Rashid (2012). Hence, the null hypothesis 2 is rejected. Finally, for interactional justice variable $(\beta=0.25)$, has a significant relationship with $\mathrm{OCB}$. This implies that the relationship between leadership and academic staff members affect the positive behavior. This finding is in line with the Erkutlu (2011), thus the null hypothesis 3 is rejected.

\section{Conclusion}

The study shows that there is a relationship between organizational justice and OCB. Hence, this finding has supported the social exchange theory that when the organization treats the employees well, they will reciprocate with OCB. Therefore, this show the good sign that Malaysian polytechnics are in good track to achieve the Polytechnic Transformation Agenda 2020. As academic staff, they are also responsible for the administration job, thus this could contribute not satisfied if the distributive justice among them are not equal. However, this finding supports that distributive justice practices in the organization are conducted well and it contributes to OCB. For procedural justice, the procedure that is not firm could increase the OCB. This is in line with a government servant policy where the general implementation used in Malaysian polytechnic administration is similar (e.g.: policy, housing loan, benefits and etc.). Furthermore, the assessment of the promotion scheme is transparent to all academic staff. This promotion requirement is available for the academic staff' members (Jabatan Pendidikan Politeknik, 2005). Besides, the facilities and most of academic staff working hours are spent with the students and procedural justice is not seen could influence their teaching sessions.

Interactional justice has significant influence on OCB. This result contrasts with Elanain (2011) study for service organizations in Dubai.. The interactional justice is the way leaders interact and motivate academic staff members. The interesting in this Malaysia polytechnics is the leaders is appointed from the academic staff who are seniors and have an excellent record. Consequently, they were well understood and experienced about the academic staff's working environment. Besides, they are participating and involved in activities held in the department or organization. Hence, this cooperation could encourage academic staff to continue exhibiting OCB. This is in line with DiPaola and Hoy (2004), the informal praise may be the best commendation for them to exhibit OCB.

For the control variables, from the four demographics involved, only age and marital status have contributed to OCB. The negative sign shows academic staffs who are single, the level of OCB is high compared to those who are married. This is where the tendency to stabilize the career in early stage is higher before they sustain with the organization. Generally, this phenomena happen because they need to prepare for the family life. In addition, the opportunity to involve in government career is limited and high competition among candidates. Age has a positive significant influence on OCB indicate that older academic staff have higher OCB. The older academic staff members have fewer needs for achievement and tend to have more social interaction with colleagues. Besides, since they have longer period with the organization have strengthened competence and leads to higher OCB. This is in in line with Maslow (1970), where middle- aged people are devoted to the fulfillment of social needs. In contrast, the goal of the young academic staff in the careers is to achieve economic security.

Finally, this study shows that academic staff fully participation is important to achieve the organization transformation. This is due to the changes in their daily work routine could affect their OCB. Therefore, the awareness is important for organizations about their academic staff requirement to sustain their working quality 


\section{References}

Bateman, T. S., \& Organ, D. W. (1983). Job satisfaction and the good soldier: The relationship between affect and employee citizenship. Academy of Management Journal, 26, 587-595.

Blau, P. (1964). Exchange and power in social life. New York: Wiley.

Bolino, M. C., Turnley, W. H., Gilstrap, J. B., \& Suazo, M. M. (2010). Citizenship under pressure: What's a "good soldier" to do? Journal of Organizational Behavior, 31, 835-855.

Burke, W. W. (2008). Organization change theory and practice. United States of America: Sage Publications.

Chua, Y. P. (2009). Statistik penyelidikan lanjutan. Malaysia: McGraw-Hill.

DiPaola, M., Tschannen, \& Moran, M. (2001). Organizational citizenship behavior in schools and its relationship to school climate. Journal of School Leadership, 11, 424-447.

DiPaola, M., \& Hoy, W. K. (2004). Organizational citizenship of faculty and achievement of high school students. The High School Journal, 88, 16-45.

Elanain, H. M. A. (2010). Testing the direct and indirect relationship between organizational justice and work outcomes in a non-Western context of the UAE. Journal of Management Development, 29, 5-27.

Erkutlu, H. (2011). The moderating role of organizational culture in the relationship between organizational justice and organizational citizenship behaviors. Leadership \& Organization Development Journal, 32, 532-554.

Hemdi, M. A., Razali, M. A., Rashid, N. N. A., \& Nordin, R. (2012). Organizational citizenship behavior of hotel employees: Investigating the impact of organizational justice. In A. Zainal, S. M. Radzi, R. Hashim, C. T. Chik, \& R. Abu. Current issues in hospitality and tourism: Research and innovations (pp. 159-164). London: Taylor \& Francis Group.

Idrus, S. H. S. (2007). The influence of organizational commitment towards organizational citizenship behaviour (OCB) among contract staffs (VOT 29) in Universiti Malaysia Perlis. (Doctoral dissertation, Universiti Utara Malaysia, 2005).

Jabatan Pendidikan Politeknik (Kementerian Pendidikan Malaysia), (2005), eSIS: Web Based Staff Information System. [Online] Available: http://www.blpk.gov.my/esis2

Jabatan Pengajian Politeknik. (2009). Hala tuju transformasi Politeknik. Malaysia: Kementerian Pengajian Tinggi.

Jafari, P., \& Bidarian, S. (2012). The relationship between organizational justice and organizational citizenship behavior. Procedia-Social and Behavioral Sciences, 47, 1815-1820

Johnson-Cramer, M. E, Parise, S., \& Cross, R. L. (2007). Managing change through networks and values. California Management Review, 49, 85-109.

Katz, D., \& Kahn, R. (1966). The social psychology of organization. New York: Wiley.

Khan, S. K., \& Rashid, M. Z. A. (2012). The mediating effect of organizational commitment in the organizational culture, leadership and organizational justice relationship with organizational citizenship behaviour: A study of academician in private higher learning institutions in Malaysia. International Journal of Business and Social Science, 3, 83-91.

Kotter, J. P. (2009). Leading change: Why transformation efforts fail. IEEE Engineering Management Review, 37, $42-48$.

Leach, T. (2009). Maybe I can fly: Nurturing personal and collective learning in professional learning communities. Pastoral Care in Education, 27, 313-323.

Lee, H. Y., \& Ahmad, K. Z. (2009). The moderating effects of organizational culture on the relationships between leadership behaviour and organizational commitment and between organizational commitment and job satisfaction and performance. Leadership \& Organization Development Journal, 30, 53-86.

Maslow, A. H. (1970). Motivation and personality. New York: Harper \& Row.

Meh, S. C., \& Nasurdin, A. M. (2009). The relationship between job resources, job demands and teacher OCB: Concept paper. [Online] Available: http://ejournal.narotama.ac.id/files/The\%20Relationships\%20Between\%20Job\%20Resources,\%20Job\%20Demands.pdf

Moon, H., Mayer, D. M., Kamdar, D., \& Takeuci, R. (2008). Me or we? The role of personality and justice as other-centered antecedents to innovative citizenship behaviors with in organizations. Journal of Applied Psychological Association, 93, 84-94.

Nguni, S., Sleegers, P., \& Denessen, E. (2006). Transformational and transactional leadership effects on teachers' job satisfaction, organizational commitment and organizational citizenship behavior in primary schools: The Tanzanian case. School Effectiveness and School Improvement, 17, 145-177.

Salleh, M., Amin, A., Muda, S., \& Halim, M. A. S. A. (2013). Fairness of performance appraisal and organizational commitment. Asia Social Science, 9, 121-128.

Seijts, G. H., \& Roberts, M. (2011). The impact of employee perceptions on change in a municipal government. Leadership \& Organization Development Journal, 2, 190-213.

Waheed, H., Salami, A. B., Ali, D. O., \& Dahlan, A. R. A. (2011). Collaborative web-based teacher professional development system: A new direction for teacher professional development in Malaysia. International Journal of Humanities and Social Science, 1, 208216.

Yaghoubi, M., Afshar, M., \& Javadi, M. (2012). A study of relationship between the organizational justice and organizational citizenship behavior among nurses in selected hospitals of Isfahan University of Medical Sciences. Iranian Journal of Nursing and Midwifery Research, 17, 456-460.

Zeinabadi, H., \& Salehi, K. (2011). Role of procedural justice, trust, job satisfaction and organizational commitment in organizational citizenship behaviour (OCB) of teachers: Proposing a modified social exchange model. Procedia-Social and Behaviorial Science, 29, 1472-1481. 